\title{
Whose (Transformative) Reality Counts? A Reply to Aoo et al.
}

\author{
Stephen Devereux and Rachel Sabates-Wheeler
}

The concept of 'transformative social protection' (TSP) was born in 2003, while we were working with the Government of Uganda and DFID on 'mainstreaming social protection' in Uganda's revised national Poverty Eradication Action Plan (PEAP). A series of interactions with government and donor officials, the Social Protection Task Force, the PEAP Secretariat and Sector Working Groups led us to observe that: (1) social protection was largely conceived in terms of a menu of instruments that were uncoordinated across sectors, expensive and likely to do little to reduce poverty or vulnerability in the long run; (2) the proposed menu (e.g. food aid distributions or targeted cash transfers) typically addressed the symptoms or consequences of natural disasters, conflict or chronic poverty, rather than addressing the underlying causes of these problems. These observations led to a suggestion that the social protection agenda should be refocused on causes rather than consequences of vulnerability, which necessarily required an understanding of the structural nature of vulnerability, and an appeal to begin policy discussions from the objectives of social protection rather than from the instruments available. The ambition was to move thinking beyond 'safety nets for basic needs' and towards 'social protection for vulnerability reduction', bringing together livelihoods thinking with a rights-based approach. While the rights agenda was not made explicit in our 2004 IDS Working Paper, the framework did open up space for linking social protection to rights, inclusion and citizenship, and we have subsequently started to think about how to do this.

The TSP approach has provoked a range of responses. Some donors, such as UNICEF and certain DFID country programmes, have drawn on it in developing their policy frameworks for social protection in specific sectors and countries. NGOs such as ActionAid have also drawn on TSP as a platform for bringing rights into the social protection discourse (see Thomson on the 'Universal Social Minimum', in this IDS Bulletin). Others have been suspicious of what seems to be an all-encompassing conceptual framework for social protection, at the same time questioning its applicability and utility on the ground. The question raised by Ken Aoo and his colleagues in their comments on TSP - 'holistic or too ambitious?' - succinctly sums up this concern about theoretical over-reach and limited practical relevance. Our 'critical reviewers' also raise more radical critiques, related to our 'neo-colonialism' in presuming what an agenda of transformation should look like for households, communities and countries that are not our own.

Let us start with the radical critique. Can we advocate for social transformation without being labelled interventionist and patronising, thereby contradicting our vision of empowerment for the socially marginalised? We would concede that arguing for transformation, by definition, requires adopting a political stance - no campaign for social justice is politically neutral. But pursuing an agenda with the aim of securing positive change for others is not necessarily condescending, even if it does imply intervening in another society. In fact, this dilemma applies equally across the entire development policy field. Every donor official who chooses to allocate resources to, say, promoting girls' education is intervening in another country with the aim of adjusting the policy priorities of other governments and the behaviour of other people. Strict neutrality in development policy is surely impossible; the only way to avoid accusations of 'cultural imperialism' is to disengage entirely from policy debates in other countries and societies.

'Transformative social protection' is not a political programme; it is a social programme grounded in a pragmatic argument: that political action might be 
required to deliver effective social protection that contributes to desirable outcomes such as poverty reduction and other Millennium Development Goals. Poverty and vulnerability are sustained through structural barriers to market access, differentiated participation in economic and political life and unequal access to services. These barriers and discriminatory practices need to be reduced or removed - otherwise social protection will never go beyond handouts that merely maintain people in their structurally disadvantaged positions - but yes, this will require meddling in politics.

Is TSP so broad that it colonises virtually all development initiatives? Our original intention was simply to elaborate an understanding of social protection that concerns itself directly with addressing 'social risk' and non-economic vulnerabilities, such as social exclusion, discrimination and violations of minority rights. Our expanded definition of social protection emphatically does not extend to all policy measures that promote livelihoods and economic growth. Instead, we highlight the potential of certain social protection measures to contribute to growth and productivity as well as to risk management and/or social equity, either through achieving both objectives simultaneously or through linkages with other interventions. A good example is a shift from food aid to cash transfers, which should provide incentives (rather than disincentives) to farmers and traders, thereby boosting domestic food production and stimulating local markets. In fact, many social protection instruments, if carefully selected and well designed, can have additional 'transformative' capacities, and this in turn is likely to lead to more sustainable poverty reduction. Conversely, if instruments are not carefully selected and well designed, the impacts can be regressive in terms of exclusion, stigmatisation (e.g. requiring beneficiaries to disclose their HIV status) and the entrenchment of poverty (e.g. mis-targeted food aid handouts that create dependency)

We would certainly agree that 'real and deep transformation' takes time, and that awareness campaigns and political lobbying are often not potent or sustained enough to bring about desired change. These concerns may be valid, but they are no justification for apathy and despondency. Instead, citizens and civil society organisations should work more closely with donors and NGOs that are implementing social protection programmes on their behalf, to find real and lasting solutions to their poverty and vulnerability that can be embedded in donor programmes, while also forcing governments to uphold their political commitments. Ultimately, national governments are responsible for delivering social protection to their citizens, and building this 'social contract' is the exit strategy that all external actors or development partners should be working towards.

Finally, some reflection would be welcome on why proponents of transformative change are frequently called to account, whereas the alternative to an agenda of social justice - usually the status quo - is typically left undefended. 